\title{
Multidimensional Analysis on the Construction of Inner-Party Supervision System
}

\begin{abstract}
Sijie Ma
Northwest University of Political Science and Law, Administrative Law School, Shaanxi, Xi'an, 710122,
\end{abstract} China

\begin{abstract}
:
In the new era, it is necessary to build a comprehensive, authoritative and efficient supervision system. We will further develop the basic theoretical system of the party's internal supervision, explore specific ways to improve its supervision ability and quality, and thoroughly study and implement the important spirit of the 19th national people's Congress. The key to the construction of the operation mechanism system of the party's internal supervision lies in taking Marxism and the theoretical system of socialism with Chinese characteristics as the "point" and the historical experience and practical application of the party's internal supervision as the "line". In the process of the research on the combination of point and line, the basic contents of the theory of the party's internal supervision and operation organization in the new era are more specific. When encountering new situations and problems, we carefully analyze and solve them. In the process of practice, effective experience is screened out to realize the link between the theoretical system and the construction of the system model.
\end{abstract}

Keywords: Inner-party supervision, Operation mechanism, System theory, Model construction.

\section{INTRODUCTION}

Inner party supervision is the core content of the party's construction, which embodies our party's fine tradition and political advantages. Since the 19th National Congress of the Communist Party of China, in the process of overall and strict administration of the party, the standardization and effectiveness level of inner-party supervision has been effectively improved through responsibility implementation, system adjustment, work innovation, etc [1]. The promulgation of the regulations on inner party supervision of the Communist Party of China is an important achievement of the institutionalization of inner party supervision and a 
guiding document for the construction of the long-term operation mechanism of inner party supervision. The operation mechanism of inner-party supervision is a dynamic process in which all the components and their sub-systems in the inner-party coordinate with each other according to certain structure and law. Therefore, it is an important task to optimize the construction of inner-party supervision system, explore and build a complete set of elements, reasonable structure and stable operation mechanism of inner-party supervision, and strengthen strict and comprehensive management of the party under the new historical conditions.

\section{ELEMENTS OF INNER-PARTY SUPERVISION MECHANISM}

The construction of operation mechanism is the key link of system construction, which is used to ensure the establishment of the system and the effective operation of the system. In terms of internal supervision, the restriction and supervision of power, the cage of system, the punishment mechanism of non corruption, the prevention mechanism and protection mechanism of non corruption has been strengthened [2]. Generally speaking, operation mechanism refers to the operation process and working mechanism of all components in the decoration chain, such as internal factors, external factors, relationship factors and relevant factors of a specific system. Inner party supervision is a process of supervising the behavior and activities of the parties, cadres and Party organizations. Its operation mechanism is a combination of static elements, directional elements of supervision action and dynamic process elements.

\subsection{Static Elements of Inner-Party Supervision Mechanism}

The static elements include the subject element, the object element and the rule element [3]. In the process of inner-party supervision, the static elements are clearly defined, so they are relatively stable, and are related to each other by the occurrence of supervision behavior.

\subsubsection{Main elements of inner-party supervision}

All kinds of Party organizations and Party members at all levels leading the supervision within the party and carrying out the supervision [4]. These supervision institutions are based on the internal supervision system of the party with different roles and responsibilities, i.e. "unified leadership of the Central Committee, comprehensive supervision of the Party committee (Party group) and special supervision of disciplinary institutions".

\subsubsection{Object elements of inner-party supervision}

Restricted objects and contents to be monitored, necessary actions and activities. The task 
of inner-party supervision is to ensure the effective implementation of the party constitution, the party constitution and the party discipline, and to maintain the unity and unity of the party [5]. All levels of organizations of the party and all its members are the objects of supervision and supervision. Moreover, as a unified body of supervision, it reflects the characteristics of internal supervision of the company. As far as the action elements are concerned, there are two general elements: abiding by the rules and regulations, maintaining the party's concentration and unity, maintaining a good style of work, and the specific elements related to the operation of power. Among the various types of objects to be monitored in the evening party, the key objects are the main organs and cadres of the party, especially the main cadres, namely the "key minority".

\subsection{Directional Elements of Inner-Party Supervision Operation Mechanism}

\subsubsection{Operation direction of inner-party supervision}

There are supervision behaviors between supervision subjects and supervision objects, forming the relationship between supervision and granting. The operation of the relation of giving and receiving refers to the influence of the governed and the class relation of the object among the parties. There are three kinds of direction relations [6]: top-down, parallel and bottom-up. The top-down supervision involves the supervision of the lower Party organizations and the higher Party organizations and punishment committees on their members; the parallel supervision involves the supervision between the party organizations at the same level and the members of the Party committee; the bottom-up supervision refers to the supervision and supervision of the superior leaders of the grass-roots party organizations and the members of the general political parties.

\subsubsection{Implementation of inner-party supervision}

Judging from the occurrence process of supervision behavior and the objects restricted by supervision, including supervision before, during and after the event. The Democratic Party's life meeting, the basic daily prevention of criticism and self-criticism, activity report, etc., the vigilance and surveillance task, through the rules and disciplines, abide by the party members, and strengthen the organizational awareness of cadres and parties [7]. The behaviors or activities of the supervised objects, such as events, supervision, public participation, process participation, and records of major events. According to the constitution of the parties, the provisions of the parties and the appropriate requirements of the discipline of the parties, the follow-up supervision shall be carried out according to the supervision by means of inspection, handling of letters and visits, responsibility of interpretation, etc. 


\subsection{Dynamic Process Elements of Inner-Party Supervision Operation Mechanism}

\subsubsection{Leadership mechanism and integration mechanism}

The internal supervision of the company is a typical group of supervision, and there are various supervision organs with different strength in different directions. Effective leadership and coordination mechanism are needed to overcome the interests and adverse effects of the relationship between the supervision objects [8]. At the same time, the internal supervision of the party will not be isolated. In terms of the implementation of supervision, it should be integrated into a complete power supervision system with the democratic supervision of the people's Congress and the CPPCC, the supervision of the judicial organs and the supervision of the supervisory organs. Leadership and solidarity need to be strengthened in all subjects.

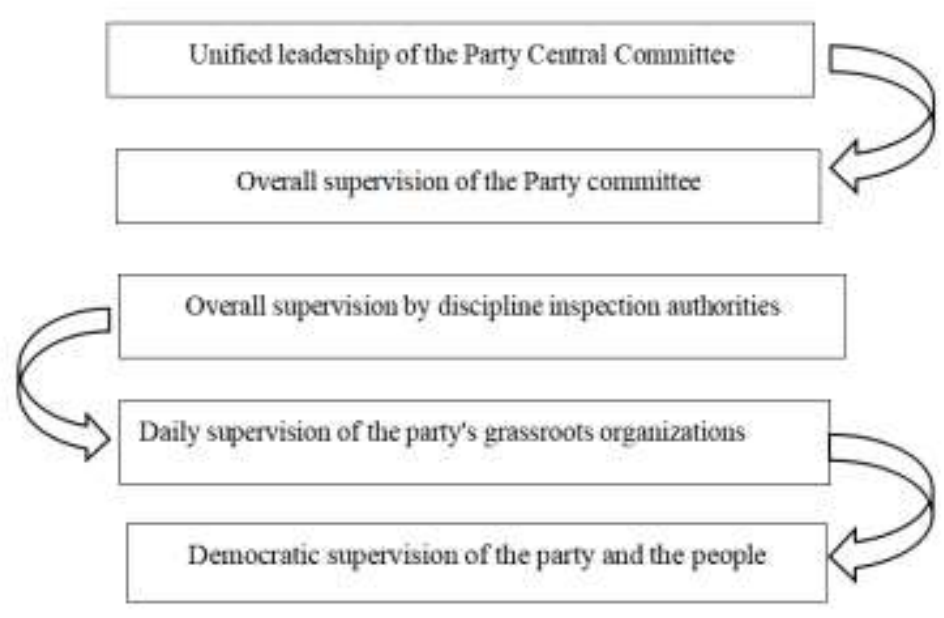

Fig.1 Supervision system of the party

\subsubsection{Responsibility and accountability mechanism}

It is difficult to stimulate the enthusiasm of inner-party supervision through positive incentives. Moreover, the positive incentive mainly comes from the responsibility and the explanation responsibility mechanism, which has the negative incentive characteristic [9]. Therefore, it is necessary to clarify the supervision responsibilities and mutual relations of the parties, and to avoid the problems of formal supervision, inaction, rhetoric and so on due to the opaque responsibilities and loss of power, allocate considerable authority and rights. At the same time, through the accountability mechanism to do a good job in supervision, the supervision situation of the supervisor is formed to urge the supervisor to strictly perform his 
duties and overcome slack.

\section{ANALYSIS ON THE FEASIBILITY AND PROCESS OF THE CONSTRUCTION OF INNER-PARTY SUPERVISION AND OPERATION MECHANISM SYSTEM}

Since the 19th National Congress of the Communist Party of China, the new central leading group has made many new theoretical explanations and institutional arrangements for the supervision and construction of the party in the new era, which contains rich systematic thoughts. First of all, we should strictly follow the basic principles and laws of dialectical materialism, and further build a perfect theoretical research system of inner-party supervision, starting with the theoretical discussion of clarifying the system elements, improving the organizational structure and improving the system measures. To realize the transformation of the research field of inner-party supervision from "micro" system to "macro" system construction.

3.1 Achieve the Innovation and Development of the Theory of Party Building with Chinese Characteristics

The objectives, principles, main lines, overall layout and objectives of the party's construction in the new era put forward by the 19th National Congress of the Communist Party of China are closely linked, interacted and promoted to form a scientific and organic whole of the party's construction in the new era. To strengthen the theoretical research on the system of inner-party supervision operation mechanism is to use scientific ideas and methods to improve the level of standardization and institutionalization, and to improve the seriousness, standardization and effectiveness of the system. In order to give full play to the overall advantages of supervision, we should work in depth and carefully to ensure the matching and connection of systems, policies, procedures, requirements and other norms. It embodies the development trend of scientific construction of inner-party supervision combining top-level design and bottom-level exploration, and realizes the organic unity of "strategy" and "standard" of strict governance of the party.

\subsection{Realize the System Integration with the Socialist Power Supervision System}

The 19th National Congress of the Communist Party of China put forward the strategic guiding ideology of "combining inner-party supervision with the supervision of state organs, democratic supervision, judicial supervision, mass supervision and public opinion supervision, and strengthening the coordination of supervision". In the socialist power supervision system, inner-party supervision has the core and pivotal role, which directly affects and restricts the role 
and effect of other forms of supervision. Inner party supervision includes the principle of democratic centralism, adhering to the strict party law over the national law, and accepting the supervision of public opinion inside and outside the party. Without the role of inner-party supervision, it will be empty talk to build a power restriction and supervision mechanism with Chinese characteristics, and the power restriction and supervision mechanism of the whole society will lose its foundation.

3.3 Process Analysis of the Construction of Inner-Party Supervision Operation Mechanism System

As a complex social system project, to build a system model that conforms to the basic characteristics and laws of the inner-party supervision mechanism is to realize the application of the method and perspective of system theory to explain the actual characteristics of practical activities, predict the future development of the object, and provide the basic links of optimization decisions. System model architecture and system design need to clarify the relationship between the system elements and optimize the composition of the elements. In particular, "the key lies in the negative feedback of system stability, information smoothness, adaptability, anti-interference ability, etc., and the control and improvement of these performances by means of reducing cycle links and attenuating noise", which finally realizes the organic combination of the principle of "quality" and the implementation of "quantity" of supervision and operation activities.

\subsection{Mode Optimization of Operation Mechanism}

From the above analysis, we can see that the operation mechanism of inner-party supervision is a complex collection of mechanism groups. From the perspective of constituent elements, there are institutional factors, institutional factors, cadre factors and cultural factors. From the perspective of function, there are some problems such as party law, internal and external supervision, and cultural concept restriction. In view of the above factors, the new inner-party supervision regulations constantly optimize the power operation mechanism, making its structure more reasonable, deployment more scientific, procedures more strict and constraints more effective. To optimize the operation mechanism of inner-party supervision is to explore the basic laws of the operation mechanism of inner-party supervision, and form a reasonable structure, scientific configuration, strict procedures and effective power supervision operation mode. Therefore, we need to pay special attention to the optimization of the operation mechanism model to ensure that the elements and functional subsystems that are interrelated, infiltrated and influenced each other can realize self-regulation, coupling and coordination, and improve the overall function of the system. Only in this way can we give full play to the role of 
the inner-party supervision system and maximize the supervision effect.

\subsection{Explore the Effective Integration of System Theory and Model System}

In the information age, the computerized implementation path of various tasks is the process of transaction model, conceptual abstract model, rational abstract model and mathematical model. Systematic scientific methods provide an intermediate transition model for the application of computer and mathematics in legal research. The system adjustment and regulation of social relations are more reasonable and timely, which must go through the transformation from social behavior parameters to mathematical model to computer simulation. There must be an intermediate link between the mathematical object and the real object. This is a system pattern composed of system methods, which is used to model a given object. The systematization of social science is the bridge from social science to digitalization and the only way to promote social science to computerization. Although the research on the operation mechanism of the inner-party supervision system in the new era is a hot issue in the current theoretical circle, the research on the implementation of the system and the construction of the model system has just begun. Although there are some academic articles in related fields, there are relatively few monographs or dissertations in the theoretical field.

\section{CONCLUSION}

At present, the research of inner-party supervision mechanism is generally based on two methods: basic theory and basic analysis, so it has some limitations. Therefore, in the process of system construction, we need to use a variety of research methods, such as comparative analysis and empirical research, to avoid one sidedness and limitations of research methods. From the perspective of the overall principle of the system method, the coordination of various factors in the communication system is conducive to revealing the scientific system and operation rules of the party's difficult supervision thoughts in the new era. The theoretical significance of inner-party supervision in the new era can be further clarified by combining historical and logical analysis methods. However, the realistic analysis and normative analysis are the key to the breakthrough of the theory.

\section{ACKNOWLEDGEMENTS}

This paper is a phased research result of the humanities and Social Science Project of Shaanxi Education Department: research on informal system of inner-Party supervision (project approval no.: 21JK0401), and is also a phased research result of a university level youth scientific research project of Northwest University of Political Science and Law: 
research on the Change Motivation of Inner-Party Supervision System from the Perspective of Informal System (Project approval: 2020QN02)

\section{REFERENCE}

[1] Xu XX, Wang JY, Huang W K (2017) Construction Schedule Risk Analysis Based on Complex System Theory: Methodology and Empirical Study. Springer Singapore

[2] Yang F, Wang A, Wu J, et al (2017) Designing credit supervision mechanism in C2B2C e-commerce based on game theory 37(8):2102-2110

[3] Spanu M (2019) State Formation under International Supervision and the Construction of Hierarchies in National Membership: A Balkan Story. Ethnopolitics, 18(2):1-17

[4] Yang RY, Chen WD (2019) Spatial Correlation, Influencing Factors and Environmental Supervision on Mechanism Construction of Atmospheric Pollution: An Empirical Study on SO 2 Emissions in China Sustainability, 2019, 11

[5] Wei F, Ge HJ, Zhang XW (2018) The Xi'an Construction Market Supervision Information System. 2018 International Conference on Smart Grid and Electrical Automation (ICSGEA)

[6] Somba K (2018) Assessment of the Ministry of Public Works Supervision Capacity in the Construction of Public Buildings in Kenya

[7] Milton J, Bennett (2017) Developmental Model of Intercultural Sensitivity. American Cancer Society

[8] Villanueva D S (2017) Strategies for Financial Reforms// Macroeconomic Policies For Stable Growth

[9] Cheng J, Cheng SC, Yang SH (2017) Greedy Constructions of Optical Queues with a Limited Number of Recirculations. IEEE Transactions on Information Theory, (99):1-1 